\title{
Impact of Emotional Intelligence, Nature of Course and Gender on Academic Stress among College Students
}

\author{
Dr. K. Subramanyam ${ }^{1 *}$
}

\section{ABSTRACT}

The aim of the present investigation is to assess the impact of emotional intelligence, nature of course and gender on academic stress among college students. Sample of the present study consists of 560 professional and non-professional college students, both male and female in Rayalaseema region of Andhra Pradesh State. To measure "Students Academic Stress Scale" was developed and standardized by Kumar Reddy (1999) and "Emotional Intelligence Scale" developed by Nutankumar Thingujam and Usha Ram (1999) were administered to the subjects. Results revealed that Academic stress is low among college students with high emotional intelligence. Non-professional course students experience little stress compared to professional course students. Gender has no significant influence on the academic stress among college students.

Keywords: Academic stress, Emotional intelligence, Professionals and Non-Professionals.

Academic stress refers to the pressure to perform well in final school examinations and competitive college entrance examinations that is experienced by students. For some students, the experience of academic stress leads to a sense of distress, which is generally manifested in a variety of psychological and behavioral problems. The experience of academic stress and adolescent distress has been identified and explored by many researchers.

Academic stress and adolescent distress has not been explored in great detail in India. It is important to note that this issue is one that affects a small proportion of Indian youth, i.e., those who are fortunate enough to attend and graduate from high school. Mental health professionals in India, however, have identified academic pressure as an acute stress factor that leads to mental distress, and in extreme cases, to suicide. Around examination time and when examination results are announced, when academic stress is very high, suicide hotlines in many cities across the country are swamped with calls.

\footnotetext{
${ }^{1}$ Post Doctoral Fellow, Department of Psychology, S.V. University, Tirupati, India *Responding Author

(C) 2016, K Subramanyam; licensee IJIP. This is an Open Access Research distributed under the terms of the Creative Commons Attribution License (http://creativecommons.org/licenses/by/2.0), which permits unrestricted use, distribution, and reproduction in any Medium, provided the original work is properly cited.
} 


\section{Impact of Emotional Intelligence, Nature of Course and Gender on Academic Stress among College Students}

Emotional intelligence is essential for interpersonal and intrapersonal relationships at school/college, at home and at work. People with high emotional quotient are expected to progress more quickly through the abilities designated and to master more of them (John Mayer and Peter Salovey, 1997). It is the capacity to create positive outcomes in the relationship with others and with oneself. Positive outcomes include joy, optimism, success in school and life.

The results are corroborated with the earlier findings of Dewan (2003); Pau and Croucher, (2003); Manhas (2004); Pau et al., (2004); Rinju George and Baby Shari (2012); Zeynep Kalyoncu et al., (2012); Ramesh Singh Bartwal and Anoj Raj (2013); Aditya Gupta, Koolwal and Sanjay Gehlot (2014); Suvarna (2014) Elham Saber (2015) which states that emotional intelligence is positively and significantly related to academic stress.

\section{Objective}

1. To assess the influence of emotional intelligence, nature of course and gender on academic stress among college students.

\section{Hypotheses}

1. There would be significant impact of emotional intelligence on academic stress among college students.

2. There would be significant impact of nature of course on academic stress among college students.

3. There would be significant impact of gender on academic stress among college students.

4. There would be significant interaction effect among emotional intelligence, nature of course and gender with regard to their academic stress among college students.

\section{Population and Sample}

The Students studying Professional and Non-Professional courses in Chittoor District of Andhra Pradesh State in India constituted the Population of the Study. Students of Professional courses like Medicine and Engineering from NIMS, Kadapa; S.V. Medical College, and S.V. University College of Engineering, Tirupati and Students of Non-professional courses (B.A., B.Sc., B.Com) from S.V. Arts College and S.P.W. Degree College, Tirupati were selected using stratified random sampling technique.

The two Psychological tools namely 1.Emotional intelligence developed by Nutankumar Thingujam, and Usha Ram (1999); 2. Students Academic Stress Scale was developed and standardized by Kumar Reddy (1999) were administered to 1200 Professional and NonProfessional Students, both Male and Female. Only the high and low Scorers on these Scales were considered and finally 560 constituted the sample of the present study and a 2X2X2 Factorial Design was adapted to analyze the results.

(c) The International Journal of Indian Psychology, ISSN 2348-5396 (e)| ISSN: 2349-3429 (p) | 121 


\section{Variables Studied}

\section{Independent Variables}

(1). Emotional Intelligence (2). Nature of Course (3). Gender

\section{Dependent Variable}

(1) Academic Stress.

\section{Tools}

(1). Emotional Intelligence Scale: The Emotional Intelligence of the Subjects was assessed by using Emotional Intelligence Scale developed by Nutankumar Thingujam, and Usha Ram (1999). (2). Assessment of Academic Stress scale: Academic Stress scale was developed and standardized by Kumar Reddy (1999).

\section{Statistical Analysis}

The obtained data were subjected to statistical analysis such as Means, SDs, and Analysis of Variance (ANOVA).

\section{RESULTS AND DISCUSSION}

Table-I: Means and SDs of scores on Academic Stress.

\begin{tabular}{|l|c|c|c|c|c|}
\hline \multirow{3}{*}{$\begin{array}{c}\text { Emotional } \\
\text { Intelligence }\end{array}$} & & \multicolumn{3}{|c|}{ Nature of Course } \\
\cline { 3 - 6 } & & \multicolumn{2}{|c|}{ Professionals } & \multicolumn{2}{c|}{ Non- Professionals } \\
\cline { 3 - 6 } & & \multicolumn{2}{|c|}{ Gender } & \multicolumn{2}{c|}{ Gender } \\
\cline { 2 - 6 } & & Male & Female & Male & Female \\
\hline \multirow{3}{*}{ Low } & Mean & $\mathbf{1 1 6 . 5 3}$ & 115.43 & 114.29 & 112.60 \\
\cline { 2 - 6 } & SD & 15.59 & 16.05 & 17.78 & 18.93 \\
\hline \multirow{2}{*}{ High } & Mean & 112.01 & 108.12 & 108.56 & $\mathbf{1 0 4 . 5 6}$ \\
\cline { 2 - 6 } & SD & 17.47 & 16.70 & 19.10 & 16.45 \\
\hline
\end{tabular}

Grand Means

Professionals $=130.02$

$$
\text { Male }=112.84
$$

Non-Professionals $=110.00$

Female $=111.27$

Low Emotional Intelligence $=114.71$

High Emotional Intelligence $=108.31$

A close observation of table-I shows that the male students studying professional courses with low emotional intelligence obtained a high score of $\mathrm{M}=116.53$ indicate that they are experiencing more academic stress compared with other groups. Female students studying non-professional courses with high emotional intelligence obtained a low score of $\mathrm{M}=104.56$ indicate that they are experiencing low academic stress compared with other groups. 


\section{Impact of Emotional Intelligence, Nature of Course and Gender on Academic Stress among College Students}

In terms of comparisons, professional students $(\mathrm{M}=130.02)$ are experiencing more academic stress than non-professional students $(\mathrm{M}=110.00)$. Male students (112.84) are experiencing more academic stress than female students $(M=111.27)$. Students with low emotional intelligence (114.71) are experiencing more academic stress than the students with high emotional intelligence students (108.31).

Table-II: Summary of ANOVA for scores on Academic stress.

\begin{tabular}{|c|c|c|c|c|}
\hline $\begin{array}{c}\text { Source of Variance } \\
\text { Emotional Intelligence (A) }\end{array}$ & $\begin{array}{l}\text { Sum of } \\
\text { Squares }\end{array}$ & df & MSS & 'F' \\
\hline Nature of Course (B) & 163.945 & 1 & 163.945 & $4.57 *$ \\
\hline Gender (C) & 16.116 & 1 & 16.116 & $0.25 @$ \\
\hline (A x B) & 2141.116 & 1 & 2141.116 & $33.67 * *$ \\
\hline (A x C) & 253.802 & 1 & 253.802 & $3.99 *$ \\
\hline (B x C) & 217.502 & 1 & 217.502 & $3.42 @$ \\
\hline (A x B x C) & 469.945 & 1 & 469.945 & $7.39 * *$ \\
\hline Within & 35102.386 & 552 & 63.591 & - \\
\hline Corrected total & 44286.313 & 559 & - & - \\
\hline $\begin{array}{c}\text { **-Significant beyond 0.01 level } \\
\text { *-Significant at 0.05 level } \\
\text { @-Not significant }\end{array}$ & & & & \\
\hline
\end{tabular}

Hypothesis-1.There would be significant influence of emotional intelligence on academic stress among college students.

It is evident from table-II that the obtained " $F$ ' value of 93.11 is significant at 0.01 level implying that emotional intelligence has significant influence on academic stress among college students. As the ' $\mathrm{F}$ ' value is significant, the hypothesis-1, which stated that emotional intelligence would significantly influence the academic stress among college students, is accepted as warranted by the results. Students with low emotional intelligence (114.71) are experiencing more academic stress than the students with high emotional intelligence students (108.31).

Students with low emotional intelligence have low capacity to reason about their emotions which will hinder their thinking which in turn affects their academic stress whereas the students with

(c) The International Journal of Indian Psychology, ISSN 2348-5396 (e)| ISSN: 2349-3429 (p) | 123 
high emotional intelligence have the capacity to reason about emotions, and these emotions enhance their thinking which in turn leads to low academic stress. Emotional intelligence skills enable people to reduce negative stress in their lives, build healthy relationships, communicate effectively, and develop emotional health.

Students with high emotional intelligence are more likely to adopt reflection and appraisal, social and interpersonal, and organization and time-management skills. Students with low emotional intelligence were more likely to engage in health damaging, poor mental health, depression, hopelessness, and suicidal ideation.

\section{Hypothesis-2.There would be significant influence of nature of course on academic stress among college students.}

It is evident from the table-II that the obtained " $\mathrm{F}$ ' value of 4.57 which is significant suggests that nature of course has significant influence on academic stress among college students. As the ' $F$ ' value is significant, the hypothesis-2 which stated the influence of nature of course on academic stress among college students is accepted as warranted by the results. It indicates that professional students $(M=130.02)$ are experiencing more academic stress than non-professional students $(\mathrm{M}=110.00)$.

Professional students at different levels of medical/engineering courses experience more stress due to academic factors, emotional factors and social factors. Academic factors are perceived as greater cause of stress. Emotional factors are dependent on person's ways of coping and social support. Social factors also found to be influencing professional course students.

The results of the present study contradictory to the findings of Hamilton and Fagot (1988) and Singh and Singh (2008); which states that nature of course is negatively related to academic stress. Findings of the present study corroborate with the earlier findings of Mannapur, et al., (2010) and Sanjeev Kumar and Bhukar (2013) which states that nature of course is positively and significantly related to academic stress.

\section{Hypothesis-3.There would be significant influence of gender on academic stress among college students.}

It is evident from table-II that the obtained ' $\mathrm{F}$ ' value of 0.25 is not significant which suggests that gender has no significant influence on academic stress among college students. As the ' $F$ ' value is not significant, the hypothesis-3 which stated that gender has significant influence on academic stress among college students is not accepted as unwarranted by the results.

Stress is a common problem to all students (both male and female students) and the way it is managed may reflect in their academic performance (Salami, 2001). Academic demands and pressure guarantee that all students will experience academic stress but how it is handled is what

(c) The International Journal of Indian Psychology, ISSN 2348-5396 (e)| ISSN: 2349-3429 (p) | 124 


\section{Impact of Emotional Intelligence, Nature of Course and Gender on Academic Stress among College Students}

matters most. Interestingly, stress tends to increase with the prospect of not being able to cope with the situation at hand, and this is the main problem that confronts many students due to their incompetence to deal with it.

Basically, the teachers have positive attitudes towards the females because they are in general mild, more studious and involved in school/college activities with dedication and commitment. Female students have been observed to be more sincere and punctual to academic work than males. All these help the female students to maintain good interpersonal relations with teachers, friends as well as parents. So they experience low academic stress in the area of teacher/pupil relationship/teaching methods.

In the Indian context most of the female students study at home or in the hostels with more facilities and time for preparation. So that they can more concentrate and discuss their doubts with their friends and teachers or tutors to overcome their academic problems. So they experience low academic stress in the area of inadequate study facilities.

Hypothesis-4.There would be significant interaction among emotional intelligence, nature of course and gender on academic stress of college students.

It is evident from the Table-II that there is no significant interaction between nature of course and gender (BXC) 3.42; in causing the effect on academic stress of college students. ' $F$ ' values for the first order interaction i.e., emotional intelligence $X$ nature of course (AXB), 33.67; emotional intelligence $\mathrm{X}$ gender (AXC), 3.99; and the second order interaction among emotional intelligence $\mathrm{X}$ nature of course $\mathrm{X}$ gender (AXBXC), 7.39 are significant. This indicates that there are significant interactions among the three independent variables i.e., emotional intelligence, nature of course and gender in causing the effect on academic stress. Hence, hypothesis- 4 which stated significant interaction among the three independent variables-emotional intelligence, nature of course and gender on academic stress among college students is accepted.

\section{CONCLUSIONS}

1. Academic stress is low among college students with high emotional intelligence.

2. Non-professional course students experience little stress compared to professional course students.

3. Gender has no significant influence on the academic stress of college students. But it has influence on components like personal inadequacy, teacher/pupil relationship/teaching methods and inadequate study facilities.

4. There is interaction among emotional intelligence, nature of course and gender in causing the effect on academic stress of college students. 


\section{Impact of Emotional Intelligence, Nature of Course and Gender on Academic Stress among College Students}

\section{Acknowledgments}

The author appreciates all those who participated in the study and helped to facilitate the research process.

\section{Conflict of Interests}

The author declared no conflict of interests.

\section{REFERENCES}

Aditya Gupta, G.D. Koolwal, Sanjay Gehlot (2014). Study of perceived stress and emotional intelligence among 1st year medical undergraduates in India. Journal of Contemporary Medical Education, 2(1), Pp: 63-67.

Dewan (2003). Effect of stress, locality and gender on selected cognitive and non-cognitive variables. Unpublished PhD., Thesis, Punjab University, Chandigarh.

Elham Saber (2015). The correlation between the intelligence and stress-coping skills in students at Islamicazad University. Indian Journal of Fundamental and Applied Life Sciences, 5 (S1), Pp: 5159-5164.

Hamilton.S and Fagot.BI. (1988). Chronic stress and coping styles: a comparison of male and female undergraduates. J PersSoc Psychol.55(5), Pp:819-823.

John Mayer and Peter Salovey, (1997). Current directions in emotional intelligence research. Handbook of emotions New York: Guilford Press. Pp: 504-520.

Mannapur B. et al (2010). A study of Psychological stress in undergraduate Medical students at S.N. Medical College, Bagalkot, Karnataka. Journal of Clinical and Diagnostic Research. 4(4), Pp: 2869-2874.

Pau., A. K. H., Croucher, R., Sohanpal, R., Muirhead, V., and K Seymour (2004). To explore how dental undergraduates with different levels of emotional intelligence (EI) cope with stress. British Dental Journal, 197 (4), Pp: 167-221.

Ramesh Singh Bartwal and Anoj Raj (2013). Academic Stress among school going adolescents in relation to their Emotional Intelligence. International Journal of Innovative Research \& Development, 2(11), Pp: 416-424.

Rinju George and Baby Shari (2012). Role of emotional intelligence on stress and coping of gifted adolescents. International Journal of Physical and Social Sciences. 2 (9), Pp: 524538.

Salami, S.D. (2001).Psychological correlates of career indecision among secondary school students. Imagination, Cognition and Personality, 9, Pp: 185-211.

Sanjeev Kumar and J. P. Bhukar (2013). The aim of this study was to investigate the stress levels and coping strategies of professional students belonging to Physical Education and Engineering professions. Journal of Physical Education and Sports Management, 4(1): Pp. 5-11. 


\section{Impact of Emotional Intelligence, Nature of Course and Gender on Academic Stress among College Students}

Singh. A and Singh.S., (2008). Stress and adjustment among professional and non-professional students. Industria Psychiatry Journal. 17 (1), Pp: 26-27.

Suvarna, V. D. (2014).The present study is concerned with the stress management and Emotional intelligence of 378 students studying $\mathrm{B}$ Ed in Mandya district. International Multidisciplinary Research Journal, 2(6), Pp: 1-5.

Zeynep Kalyoncu, Semra Guney, Mahmut Arslan, Salih Guney and Evren Ayranci (2012). Analysis of the relationship between emotional Intelligence and stress caused by the Organization: a study of nurses. Business Intelligence Journal, 5(2), Pp: 334-346.

How to cite this article: K Subramanyam (2016), Impact of Emotional Intelligence, Nature of Course and Gender on Academic Stress among College Students, International Journal of Indian

Psychology, Volume 3, Issue 4, No. 60, ISSN 2348-5396 (e), ISSN: 2349-3429 (p), DIP: 18.01.089/20160304, ISBN: 978-1-365-26308-8

(C) The International Journal of Indian Psychology, ISSN 2348-5396 (e) | ISSN: 2349-3429 (p) | 127 